\title{
Oral Testofen, L-Citrulline, Resveratrol, and Caffeine Supplement Drink Improves Sexual Function in Men with Phosphodiesterase 5 Inhibitors: Randomized, Double-Blind, Placebo-Controlled Crossover Pilot Study
}

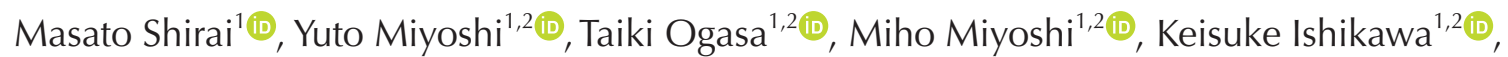 \\ Ippei Hiramatsu ${ }^{1,2}$ (D) Yuka Uesaka $^{1}$, Taiji Nozaki ${ }^{1}$, Taro Koyama $^{3}$ (D) Akira Tsujimura $^{1}$ (i) \\ ${ }^{1}$ Department of Urology, Juntendo University Urayasu Hospital, Chiba, ${ }^{2}$ Department of Urology, Juntendo University, Graduate School of \\ Medicine, ${ }^{3}$ D Clinic Tokyo Men's, Tokyo, Japan
}

\begin{abstract}
Purpose: Sexuality is very important for men's health. Currently, phosphodiesterase type 5 inhibitors (PDE5i) remain the firstline therapy for erectile dysfunction, and no other oral drugs or drinks are approved and used clinically to treat male libido or orgasm dysfunction. In reference to a pharmaceutical dosage document, growing health consciousness is said to have boosted yearly sales of supplement drinks to more than 170 billion yen (1.58 billion US dollars) in Japan. We have created a supplement drink comprised of testofen, L-citrulline, resveratrol, and caffeine. We hypothesized that our supplement drink would be effective for men with sexual dysfunction, and especially libido dysfunction.

Materials and Methods: In this study, men with sexual dysfunction received a placebo drink for 14 days or our supplement drink (testofen, $600 \mathrm{mg} / \mathrm{d}$; L-citrulline, $800 \mathrm{mg} / \mathrm{d}$; resveratrol, $300 \mathrm{mg} / \mathrm{d}$; and caffeine, $40 \mathrm{mg} / \mathrm{d}$ ) for another 14 days separated by a 7-day washout period. Patients continued on-demand use of PDE5i. The International Index of Erectile Function (IIEF) score and adverse events were assessed.

Results: Twenty patients aged 30-47 years old were enrolled in and concluded the study with no adverse events experienced. The IIEF domains of desire frequency, erection frequency, erection firmness, erection confidence, intercourse satisfaction, ejaculation frequency, orgasm frequency, and overall satisfaction were significantly improved with our supplement drink.

Conclusions: This is the first study to show that our supplement drink may not only be effective for erection but also for libido, orgasm, and ejaculation.
\end{abstract}

Keywords: Caffeine; Citrulline; Resveratrol; Sexual dysfunction, physiological; Trigonella

This is an Open Access article distributed under the terms of the Creative Commons Attribution Non-Commercial License (http://creativecommons.org/licenses/by-nc/4.0) which permits unrestricted non-commercial use, distribution, and reproduction in any medium, provided the original work is properly cited.

Received: Jul 11, 2020 Revised: Sep 24, 2020 Accepted: Oct 5, 2020 Published online Oct 27, 2020

Correspondence to: Akira Tsujimura (iD https://orcid.org/0000-0002-3821-5184

Department of Urology, Juntendo University Urayasu Hospital, 2-1-1 Tomioka, Urayasu, Chiba 279-0021, Japan.

Tel: +81-47-353-3111, Fax: +81-47-353-6511, E-mail: atsujimu@juntendo.ac.jp 


\section{INTRODUCTION}

Sexuality is very important for men's health [1]. Men with erectile dysfunction (ED) report low rates of quality of life [1]. Thus, treatment for ED is very important for improved quality of life. Libido dysfunction and orgasmic dysfunction are also important aspects of men's quality of life. In general, treatment for male libido dysfunction or orgasmic dysfunction is challenging. In the treatment of female libido dysfunction, flibanserin is the only approved oral drug [2]. Testosterone replacement therapy (TRT) is the only approved medical treatment that improves libido in hypogonadal men with sexual dysfunction [3]. However, men with sexual dysfunction and normal testosterone levels should not be offered TRT [4]. Additionally, in the treatment of male libido or orgasm dysfunction, no oral drugs or drinks are approved and used clinically. Currently, vacuum erection devices, intracavernous injections, and surgical penile prosthesis implantation are appropriate treatments for $\mathrm{ED}$ [5] if phosphodiesterase type 5 inhibitors (PDE5i) are not effective. However, as very few Japanese patients choose these therapies [6], it is extremely important that sexual function be improved by oral administration of effective agents.

Testofen is a specialized extract from Trigonella foenum-graecum seeds that reduces age-related symptoms in healthy aging males [7]. Significant androgenic activity in men is achieved with Testofen supplementation [8] through its increase of testosterone and free testosterone levels [9].

Caffeine is an alkaloid present in the everyday diet, such as coffee and tea. It is a nonselective phosphodiesterase inhibitor that raises the levels of intracellular cyclic guanosine monophosphate (cGMP) and cyclic adenosine monophosphate [10]. Caffeine improved sexual function in animal studies [11], but few such studies have been fully performed on humans with sexual dysfunction.

We showed that combination therapy with an Lcitrulline and resveratrol capsule with on-demand use of PDE5i is effective in ED patients [12]. In reference to a pharmaceutical dosage document, growing health consciousness is said to have boosted yearly sales of supplement drinks to more than 170 billion yen (1.58 billion US dollars) in Japan [13]. We have created a supplement drink containing testofen, L-citrulline, resveratrol, and caffeine. We hypothesized that our supplement drink would be effective for patients with sexual dysfunction and especially libido dysfunction. Therefore, we investigated the efficacy of our supplement drink in improving male sexual function.

\section{MATERIALS AND METHODS}

We recruited 20 patients who visited our clinics specializing in sexual function to particpate in this randomized, double-blind, placebo-controlled crossover pilot study. Men with sexual dysfunction (International Index of Erectile Function [IIEF]-Erectile Function score $<25$ and IIEF-11 (desire frequency) and IIEF-12 (desire level) scores of $<3$ ) despite their on-demand use of PDE5i received a placebo drink for 14 days or our supplement drink (testofen $600 \mathrm{mg} / \mathrm{d}$, L-citrulline 800

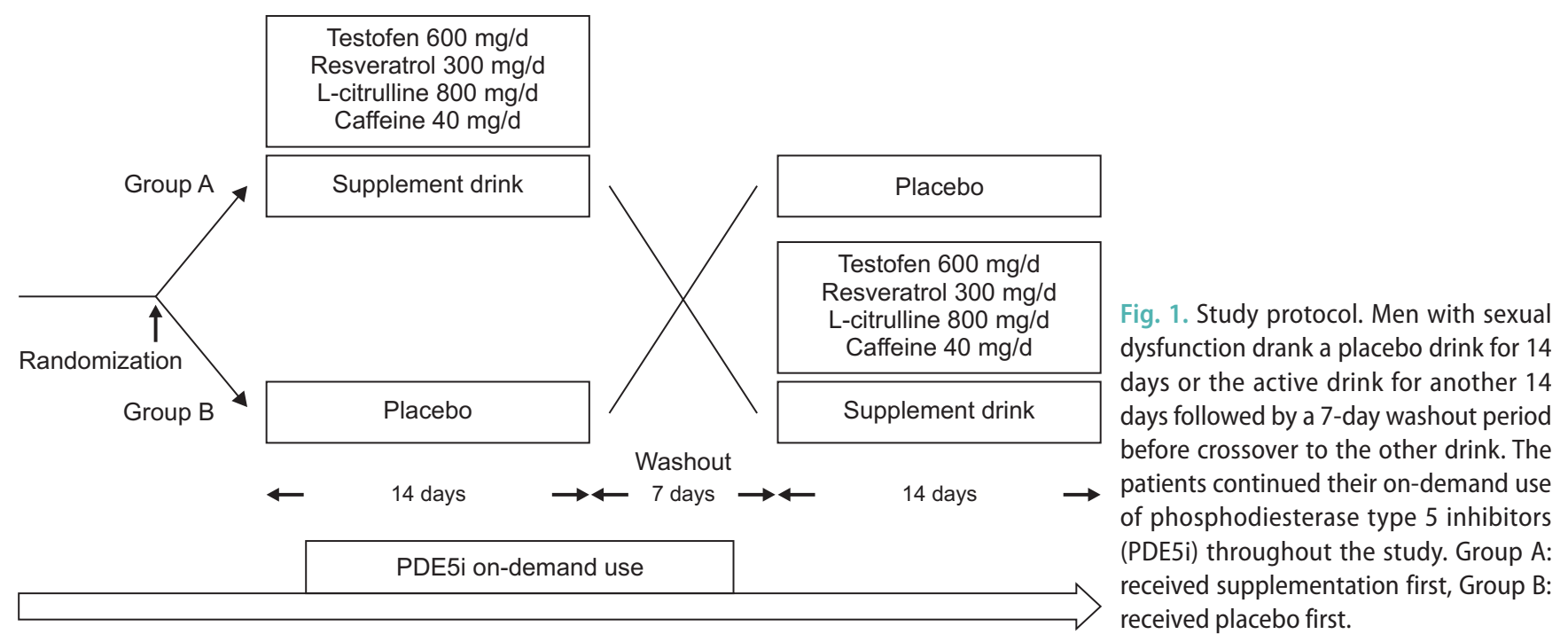


$\mathrm{mg} / \mathrm{d}$, resveratrol $300 \mathrm{mg} / \mathrm{d}$, and caffeine $40 \mathrm{mg} / \mathrm{d}$ ) for another 14 days, separated by a 7-day washout period. The patients continued their on-demand use of PDE5i (Fig. 1). The 50-mL supplement drink or 50-mL placebo drink was drunk once daily after a meal. The patients were randomly divided into two groups (A group, men receiving the supplement drink first; and B group, men receiving the placebo first). Randomization was centralized at Juntendo University Urayasu Hospital and performed by a simple randomization method using a computed random number table. The supplement and placebo drinks were prepared by Angfa, Inc. (Tokyo, Japan).

The testofen, L-citrulline, resveratrol, and caffeine at the above-mentioned doses were mixed with diluting water and a sweetener, a flavoring agent, and a stabilizing agent. The four active agents were not added to the placebo drink. The exclusion criteria in this study were patients who underwent radical prostatectomy and those allergic to chickpeas.

We evaluated sexual function with the IIEF and erection hardness score (EHS). Both measures have been validated as tools for the assessment of sexual function [14,15]. Japanese versions of both questionnaires have been validated [6]. The self-reported questionnaires were collected from the participants in the clinic. Because our supplement drink was commercially prepared, a medical doctor evaluated all patients to assess their medical condition and adverse events without performing blood tests.

\section{Main outcome measures}

The main outcome measures were improvement of the IIEF total score and libido (IIEF-11 [desire frequency] score and IIEF-12 [desire level] score).

\section{Secondary outcome measures}

The secondary outcome measures were improvement of erection (IIEF-1, -2, -3, -4, -5, and -15), orgasm (IIEF-9 and -10), intercourse satisfaction (IIEF-6, -7, and -8), and overall satisfaction (IIEF-13 and -14).

\section{Ethics statement and informed consent}

The study protocol complied with Good Clinical Practices, the Declaration of Helsinki (2013), and applicable Institutional Review Board regulations. The protocol was registered in the University Hospital Medical Information-Clinical Trials Registration (UMIN number:
UMIN000028816). The Institutional Review Board of the Juntendo University Urayasu Hospital approved the protocol (approval number: 30-007). Informed consent was obtained from the study participants prior to beginning any of the study-related procedures or medications.

\section{Statistical analysis}

Data are presented as the mean \pm standard error. A repeated measure analysis of variance was used to determine statistical significance. A p-value of $<0.05$ was considered to indicate statistical significance. Statistical analysis was performed with IBM SPSS Statistics for Macintosh, Japanese ver. 25 (IBM Japan, Tokyo, Japan).

\section{RESULTS}

Twenty men aged $30-47$ years (40.0 \pm 1.3 years) were enrolled in the study and began treatment (Table 1), and all 20 men completed the study without experiencing any adverse events (group $\mathrm{A}, \mathrm{n}=10$; group $\mathrm{B}, \mathrm{n}=10$ ). The number of men with ED overlap using on-demand PDE5i included 17 men using sildenafil, 7 men using tadalafil, and 2 men using vardenafil (Table 1). None of the men with ED used tadalafil once daily for lower urinary tract symptoms (LUTS).

The mean IIEF total score of the men taking our supplement drink was significantly greater than the baseline score and that of the men taking the placebo drink ( $<<0.001, p=0.025$, respectively) (Table 2).

In the domains of IIEF-1, -2, -7, -9, -10, -13, and -15, the mean scores with our supplement drink increased significantly compared with those at baseline and with

Table 1. Patient demographics at baseline

\begin{tabular}{lccc}
\hline \multicolumn{1}{c}{ Variable } & $\begin{array}{c}\text { Group A } \\
(\mathrm{n}=10)\end{array}$ & $\begin{array}{c}\text { Group B } \\
(\mathrm{n}=10)\end{array}$ & p-value \\
\hline Age $(\mathrm{y})$ & $40.40 \pm 1.89$ & $39.60 \pm 1.83$ & 0.77 \\
IIEF total & $19.10 \pm 1.94$ & $21.20 \pm 1.32$ & 0.83 \\
EHS & $2.00 \pm 0.15$ & $2.40 \pm 0.27$ & 0.21 \\
Duration of ED (mo) & $14.68 \pm 7.54$ & $49.79 \pm 17.67$ & 0.14 \\
On-demand PDE5i (S/T/V) & $8 / 2 / 0$ & $9 / 5 / 2$ & - \\
\hline
\end{tabular}

Values are presented as mean \pm standard error or number only. Group A: received supplementation first, Group B: received placebo first, IIEF: International Index of Erectile Function, EHS: erection hardness score, ED: erectile dysfunction, PDE5i: phosphodiesterase type 5 inhibitor, S: sildenafil, T: tadalafil, V: vardenafil. 
Table 2. Assessment of the IIEF domains in baseline, placebo, and supplement drink groups

\begin{tabular}{lrcc}
\hline Variable & Baseline & Placebo & Supplement drink \\
\hline IIEF total & $20.15 \pm 1.17$ & $38.40 \pm 3.16^{\mathrm{a}}$ & $46.05 \pm 3.37^{\mathrm{a}, \mathrm{b}}$ \\
IIEF-EF & $7.75 \pm 0.65$ & $16.10 \pm 1.62^{\mathrm{a}}$ & $19.65 \pm 1.77^{\mathrm{a}, \mathrm{b}}$ \\
IIEF-IS & $2.40 \pm 0.44$ & $5.90 \pm 0.67^{\mathrm{a}}$ & $7.50 \pm 0.69^{\mathrm{a}, \mathrm{b}}$ \\
IIEF-OF & $3.75 \pm 0.48$ & $5.60 \pm 0.60^{\mathrm{a}}$ & $7.25 \pm 0.60^{\mathrm{a}, \mathrm{b}}$ \\
IIEF-SD & $3.70 \pm 0.27$ & $5.35 \pm 0.38^{\mathrm{a}}$ & $5.55 \pm 0.38^{\mathrm{a}}$ \\
IIEF-OS & $2.55 \pm 0.24$ & $5.45 \pm 0.28^{\mathrm{a}}$ & $6.10 \pm 0.36^{\mathrm{a}}$ \\
SHIM & $5.60 \pm 0.41$ & $13.05 \pm 1.35^{\mathrm{a}}$ & $16.25 \pm 1.51^{\mathrm{a}, \mathrm{b}}$ \\
EHS & $2.20 \pm 0.16$ & $2.80 \pm 0.16^{\mathrm{a}}$ & $3.00 \pm 0.15^{\mathrm{a}}$ \\
\hline
\end{tabular}

Values are presented as mean \pm standard error.

IIEF: International Index of Erectile Function, IIEF-EF: IIEF-Erectile Function, IIEF-IS: IIEF-Intercourse Satisfaction, IIEF-OF: IIEF-Orgasmic Function, IIEF-SD: IIEF-Sexual Desire, IIEF-OS: IIEF-Overall Satisfaction, SHIM: Sexual Health Inventory for Men, EHS: erection hardness score.

${ }^{a} p<0.05$ compared with baseline. ${ }^{b} p<0.05$ compared with placebo.

the placebo drink (Table 3). In the domains of IIEF-3, -6 , and, -11 , the mean scores of our supplement drink increased significantly compared with the baseline scores, whereas they did not increase significantly compared with baseline scores for the placebo drink (Table 3).

The mean EHS of the men taking our supplement drink was significantly greater than the baseline score ( $p=0.001$ ), as was the mean EHS of the men taking the placebo $(p=0.002)$. However, the change between the EHS with our supplement drink and that with the placebo was not significantly different $(\mathrm{p}=0.157)$ (Table 2 ).

\section{DISCUSSION}

We investigated the efficacy of a supplement drink containing testofen, L-citrulline, resveratrol, and caffeine in improving sexual function, especially libido, in men with sexual dysfunction. The present study revealed significant improvement in the IEF-total score; the frequency of desire, erection, intercourse, orgasm, and ejaculation; erection firmness, erection confidence, penetration ability, intercourse satisfaction, and overall satisfaction. The results clearly showed that our supplement drink can rescue libido and erectile, orgasmic, and ejaculatory function in patients taking PDE5i. This is the first study to show that our supplement drink may be effective in improving libido, erection, orgasm, and ejaculation.

Our previous study using L-citrulline and transres-
Table 3. Assessment of the IIEF domains in baseline, placebo, and supplement drink groups

\begin{tabular}{lccc}
\hline Variable & Baseline & Placebo & Supplement drink \\
\hline IIEF-1 & $1.60 \pm 0.23$ & $2.75 \pm 0.30^{\mathrm{a}}$ & $3.35 \pm 0.28^{\mathrm{a}, \mathrm{b}}$ \\
IIEF-2 & $1.80 \pm 0.20$ & $2.70 \pm 0.33^{\mathrm{a}}$ & $3.40 \pm 0.33^{\mathrm{a}, \mathrm{b}}$ \\
IIEF-3 & $1.25 \pm 0.26$ & $2.60 \pm 0.35$ & $3.20 \pm 0.36^{\mathrm{a}}$ \\
IIEF-4 & $0.80 \pm 0.16$ & $2.60 \pm 0.34^{\mathrm{a}}$ & $3.20 \pm 0.36^{\mathrm{a}}$ \\
IIEF-5 & $0.80 \pm 0.16$ & $2.85 \pm 0.35^{\mathrm{a}}$ & $3.45 \pm 0.36^{\mathrm{a}}$ \\
IIEF-6 & $0.80 \pm 0.16$ & $1.25 \pm 0.16$ & $1.55 \pm 0.20^{\mathrm{a}}$ \\
IIEF-7 & $0.70 \pm 0.13$ & $2.30 \pm 0.33^{\mathrm{a}}$ & $3.15 \pm 0.36^{\mathrm{a}, \mathrm{b}}$ \\
IIEF-8 & $0.90 \pm 0.18$ & $2.35 \pm 0.26^{\mathrm{a}}$ & $2.80 \pm 0.28^{\mathrm{a}}$ \\
IIEF-9 & $2.00 \pm 0.25$ & $3.00 \pm 0.31^{\mathrm{a}}$ & $3.85 \pm 0.28^{\mathrm{a}, \mathrm{b}}$ \\
IIEF-10 & $1.75 \pm 0.24$ & $2.60 \pm 0.30^{\mathrm{a}}$ & $3.40 \pm 0.34^{\mathrm{a}, \mathrm{b}}$ \\
IIEF-11 & $1.80 \pm 0.16$ & $2.65 \pm 0.24$ & $2.75 \pm 0.25^{\mathrm{a}}$ \\
IIEF-12 & $1.90 \pm 0.14$ & $2.70 \pm 0.16^{\mathrm{a}}$ & $2.80 \pm 0.16^{\mathrm{a}}$ \\
IIEF-13 & $1.20 \pm 0.12$ & $2.70 \pm 0.15^{\mathrm{a}}$ & $3.10 \pm 0.19^{\mathrm{a}, \mathrm{b}}$ \\
IIEF-14 & $1.35 \pm 0.13$ & $2.75 \pm 0.14^{\mathrm{a}}$ & $3.00 \pm 0.18^{\mathrm{a}}$ \\
IIEF-15 & $1.50 \pm 0.17$ & $2.60 \pm 0.20^{\mathrm{a}}$ & $3.05 \pm 0.24^{\mathrm{a}, \mathrm{b}}$ \\
\hline
\end{tabular}

Values are presented as mean \pm standard error.

IIEF: International Index of Erectile Function.

${ }^{a} p<0.05$ compared with baseline. ${ }^{b} p<0.05$ compared with placebo.

veratrol revealed significant improvements in the Sexual Health Inventory for Men-total score, confidence in and firmness of erection, and intercourse satisfaction. Maintenance frequency and ability were also improved after the supplementation although not significantly. Our previous combination therapy might have been more effective in improving confidence and satisfaction [12]. However, the present study revealed reproducible results of the use of resveratrol and L-citrulline for ED patients with PDE5i.

A previous study using testofen at $600 \mathrm{mg} / \mathrm{d}$ reported significant improvements in sexual cognition, arousal, and behavior, and in orgasm in healthy aging males and also showed that sexual satisfaction was associated with better quality of life [16]. However, in another previous study also using testofen at the same dose, there were no changes in sexual cognition, sexual behavior, or orgasm in healthy aging males [7]. We speculated that the results of the present study showed greater effect than those of this previous study because the present study included men with low libido. Potential mechanisms of testofen include a possible increase in serum testosterone, increased testicular sensitivity to luteinizing hormone, and increased synthesis of testosterone or a reduction in testosterone catabolism [7].

Oral L-citrulline supplementation increases the serum level of L-arginine and nitric oxide production 
[17]. L-citrulline improved intracavernous and mean arterial pressures, the ratio of smooth muscle to collagen, and serum levels of nitrogen oxides in an animal ED model [18]. One clinical study reported significant improvement in EHS from 3 to 4 in $50 \%$ of men when they took L-citrulline and a significant increase in the mean number of intercourses per month compared with baseline, $2.3 \pm 1.37$ versus $1.37 \pm 0.93$ [19].

Resveratrol increases endothelial nitric oxide synthase expression [20] and improves endothelial function by activation of sirtuin 1 , which then promotes endothelium-dependent vascular relaxation [21]. Resveratrol could potentially be an effective treatment to prevent atherosclerotic change, increase blood testosterone, and provide a relaxing effect in the corpus cavernosum, as observed in hypercholesterolemic rabbits [22]. Resveratrol also elevated the intracellular cGMP level in the human corpus cavernosum smooth muscle cells [23]. Combination treatment with resveratrol and PDE5i had a synergistic effect in improving erectile function in rat model of $\mathrm{ED}$ [23].

Maintenance frequency, maintenance ability, intercourse enjoyment, desire level, and relationship satisfaction were all improved significantly after the supplement drink compared with baseline. However, these factors also improved significantly after the placebo drink compared with baseline, and the difference between the two drinks was not significant. In a previous randomized placebo-controlled study, the greatest placebo response occurred in participants younger than 45 years old [24]. Notable placebo effects have been reported in various therapeutic areas, especially in clinical investigations using patient-reported outcome measures [25]. We speculated that the placebo effects were as high as or beyond our expectation because the participants of the present study were young men with a mean age of 40.0 years old.

The applied dose of testofen in the present study was $600 \mathrm{mg} / \mathrm{d}$. The safety of testofen was assessed by oral toxicity studies using acute $(2,500 \mathrm{mg} / \mathrm{kg}$ for 14 days $)$ and subchronic (1,000 mg/kg for 90 days) administration [26]. Previous studies reported that testofen administered at a dose of $600 \mathrm{mg} / \mathrm{d}$ is safe and effective in healthy aging males [7,16]. Thus, we used $600 \mathrm{mg}$ of testofen in the supplement drink.

The applied dose of L-citrulline in the present and previous studies was $800 \mathrm{mg} / \mathrm{d}$. At the time of these studies, this was the highest dose available in Japan
(Kyowa Hakko Bio, Ibaragi, Japan). The safety of Lcitrulline has been evaluated in patients $(1.5 \mathrm{~g} / \mathrm{d})$ and rats (approximately $2 \mathrm{~g} / \mathrm{d}$ ) with $\mathrm{ED}[18,19]$. No side effects have been reported following the administration of citrulline as an oral supplement at doses up to $15 \mathrm{~g}$ [27].

The applied dose of resveratrol in the present study was $300 \mathrm{mg} / \mathrm{d}$, the same as that used in our previous study in which we calculated a dose of $5 \mathrm{mg} / \mathrm{kg}$ in both human and rat studies [12,23]. We also evaluated its safety in patients and rats with ED [23]. Another previous study reported gastrointestinal side effects in a large number of participants taking resveratrol doses of $2,500 \mathrm{mg} / \mathrm{d}$ or more, indicating that doses at or above this level may not be tolerated chronically, and that a dose of $450 \mathrm{mg} / \mathrm{d}$ can be considered safe for a $60-\mathrm{kg}$ individual [28]. We considered the dose administered in our study to be safe and effective.

The applied dose of caffeine in the present study was $40 \mathrm{mg} / \mathrm{d}$. Consumption of caffeine in healthy adults up to $400 \mathrm{mg} / \mathrm{d}$ is not associated with overt, adverse cardiovascular effects, reproductive and developmental effects, other acute effects, or bone status [29]. Additionally, we used the 40-mg dose of caffeine in the supplement drink to prevent insomnia.

Despite being a prospective, placebo-controlled study, the present study has some limitations. First, this twoinstitution study with a small sample size was short, lasting only 5 weeks. We will be planning a longerduration study that includes more institutions. Second, this study excluded ED patients taking tadalafil once daily for LUTS, which is an effective and well-tolerated medical treatment for patients with these conditions [30]. Daily use of PDE5i may be more effective in treating ED treatment combined with testofen, L-citrullines, resveratrol, and caffeine. Third, information on patient comorbidities that might affect sexual function, such as diabetes and neurologic disease was lacking. Fourth, we did not have data on the use of our supplement drink alone, not in combination with PDE5i. Fifth, we did not measure hormonal levels before and after treatment. We will be planning a study that includes such data. Sixth, the participants of the present study were young men. We could not recruit a different participant cohort, which might have been able to minimize the placebo effect. 


\section{CONCLUSIONS}

This is the first study to show that our supplement drink may not only be effective for erection treatment in men with ED along with the added on-demand use of PDE5i but also effective in improving libido, orgasm, and ejaculation. The present results showed that our supplement drink may be a possible treatment option for these patients.

\section{Conflict of Interest}

The authors have nothing to disclose.

\section{Author Contribution}

Conceptualization: MS, AT. Data curation: MS, TK, AT. Formal analysis: MS, AT. Funding acquisition: MS, AT. Investigation: MS, AT. Methodology: MS, AT. Project administration: MS, AT. Resources: MS, AT. Software: MS, AT. Supervision: YM, TO, MM, KI, IH, YU, TN, TK. Validation: MS, AT. Visualization: MS, AT. Writing - original draft: MS, AT. Writing - review \& editing: MS, AT.

\section{Data Sharing Statement}

The data analyzed for this study have been deposited in HARVARD Dataverse and are available at https://doi. org/10.7910/DVN/T5URB6.

\section{REFERENCES}

1. Sand MS, Fisher W, Rosen R, Heiman J, Eardley I. Erectile dysfunction and constructs of masculinity and quality of life in the multinational Men's Attitudes to Life Events and Sexuality (MALES) study. J Sex Med 2008;5:583-94.

2. Derogatis LR, Komer L, Katz M, Moreau M, Kimura T, Garcia M Jr, et al.; VIOLET Trial Investigators. Treatment of hypoactive sexual desire disorder in premenopausal women: efficacy of flibanserin in the VIOLET Study. J Sex Med 2012;9:107485.

3. Corona G, Goulis DG, Huhtaniemi I, Zitzmann M, Toppari J, Forti G, et al. European Academy of Andrology (EAA) guidelines on investigation, treatment and monitoring of functional hypogonadism in males: endorsing organization: European Society of Endocrinology. Andrology 2020;8:970-87.

4. Boloña ER, Uraga MV, Haddad RM, Tracz MJ, Sideras K, Kennedy CC, et al. Testosterone use in men with sexual dys- function: a systematic review and meta-analysis of randomized placebo-controlled trials. Mayo Clin Proc 2007;82:20-8.

5. Hatzimouratidis K, Salonia A, Adaikan G, Buvat J, Carrier S, El-Meliegy A, et al. Pharmacotherapy for erectile dysfunction: recommendations from the fourth International Consultation for Sexual Medicine (ICSM 2015). J Sex Med 2016;13:465-88.

6. Japanese Society for Sexual Medicine, The Japanese Urological Association. [JSSM guidelines for erectile dysfunction]. 3rd ed. Tokyo: RichHill Medical Inc.; 2018. Japanese.

7. Rao A, Steels E, Inder WJ, Abraham S, Vitetta L. Testofen, a specialised Trigonella foenum-graecum seed extract reduces age-related symptoms of androgen decrease, increases testosterone levels and improves sexual function in healthy aging males in a double-blind randomised clinical study. Aging Male 2016;19:134-42.

8. Wankhede S, Mohan V, Thakurdesai P. Beneficial effects of fenugreek glycoside supplementation in male subjects during resistance training: a randomized controlled pilot study. J Sport Health Sci 2016;5:176-82.

9. Wilborn C, Taylor L, Poole C, Foster C, Willoughby D, Kreider R. Effects of a purported aromatase and $5 \alpha$-reductase inhibitor on hormone profiles in college-age men. Int J Sport Nutr Exerc Metab 2010;20:457-65.

10. Cappelletti S, Piacentino D, Sani G, Aromatario M. Caffeine: cognitive and physical performance enhancer or psychoactive drug? Curr Neuropharmacol 2015;13:71-88.

11. Yang R, Wang J, Chen Y, Sun Z, Wang R, Dai Y. Effect of caffeine on erectile function via up-regulating cavernous cyclic guanosine monophosphate in diabetic rats. J Androl 2008;29:586-91.

12. Shirai M, Hiramatsu I, Aoki Y, Shimoyama H, Mizuno T, Nozaki T, et al. Oral L-citrulline and transresveratrol supplementation improves erectile function in men with phosphodiesterase 5 inhibitors: a randomized, double-blind, placebocontrolled crossover pilot study. Sex Med 2018;6:291-6.

13. INTAGE. [The energy drink market find favor with young men] [Internet]. Tokyo: INTAGE Inc.; c2020 [cited 2020 Sep 14]. Available from: https://www.intage.co.jp/gallery/energydrink/. Japanese.

14. Rosen RC, Cappelleri JC, Gendrano N 3rd. The International Index of Erectile Function (IIEF): a state-of-the-science review. Int J Impot Res 2002;14:226-44

15. Mulhall JP, Goldstein I, Bushmakin AG, Cappelleri JC, Hvidsten K. Validation of the erection hardness score. J Sex Med 2007;4:1626-34.

16. Steels E, Rao A, Vitetta L. Physiological aspects of male libido enhanced by standardized Trigonella foenum-graecum extract and mineral formulation. Phytother Res 2011;25:1294- 
300.

17. Schwedhelm E, Maas R, Freese R, Jung D, Lukacs Z, Jambrecina A, et al. Pharmacokinetic and pharmacodynamic properties of oral L-citrulline and L-arginine: impact on nitric oxide metabolism. Br J Clin Pharmacol 2008;65:51-9.

18. Hotta Y, Shiota A, Kataoka T, Motonari M, Maeda Y, Morita $\mathrm{M}$, et al. Oral L-citrulline supplementation improves erectile function and penile structure in castrated rats. Int J Urol 2014;21:608-12.

19. Cormio L, De Siati M, Lorusso F, Selvaggio O, Mirabella L, Sanguedolce F, et al. Oral L-citrulline supplementation improves erection hardness in men with mild erectile dysfunction. Urology 2011;77:119-22.

20. Wallerath T, Deckert G, Ternes T, Anderson H, Li H, Witte K, et al. Resveratrol, a polyphenolic phytoalexin present in red wine, enhances expression and activity of endothelial nitric oxide synthase. Circulation 2002;106:1652-8.

21. Mattagajasingh I, Kim CS, Naqvi A, Yamamori T, Hoffman TA, Jung SB, et al. SIRT1 promotes endothelium-dependent vascular relaxation by activating endothelial nitric oxide synthase. Proc Natl Acad Sci U S A 2007;104:14855-60.

22. Soner BC, Murat N, Demir O, Guven H, Esen A, Gidener S. Evaluation of vascular smooth muscle and corpus cavernosum on hypercholesterolemia. Is resveratrol promising on erectile dysfunction? Int J Impot Res 2010;22:227-33.

23. Fukuhara S, Tsujimura A, Okuda H, Yamamoto K, Takao T, Miyagawa $\mathrm{Y}$, et al. Vardenafil and resveratrol synergistically enhance the nitric oxide/cyclic guanosine monophosphate pathway in corpus cavernosal smooth muscle cells and its therapeutic potential for erectile dysfunction in the streptozotocin-induced diabetic rat: preliminary findings. J Sex Med
2011;8:1061-71.

24. Mulhall JP, Carlsson M, Stecher V, Tseng LJ. Predictors of erectile function normalization in men with erectile dysfunction treated with placebo. J Sex Med 2018;15:866-72.

25. Hróbjartsson A, Gøtzsche PC. Is the placebo powerless? An analysis of clinical trials comparing placebo with no treatment. N Engl J Med 2001;344:1594-602.

26. Sureshkumar D, Begum S, Johannah NM, Maliakel B, Krishnakumar IM. Toxicological evaluation of a saponin-rich standardized extract of fenugreek seeds (FenuSMART ${ }^{\circledR}$ ): acute, sub-chronic and genotoxicity studies. Toxicol Rep 2018;5:1060-8.

27. Moinard C, Nicolis I, Neveux N, Darquy S, Bénazeth S, Cynober L. Dose-ranging effects of citrulline administration on plasma amino acids and hormonal patterns in healthy subjects: the Citrudose pharmacokinetic study. Br J Nutr 2008;99:855-62.

28. Smoliga JM, Vang O, Baur JA. Challenges of translating basic research into therapeutics: resveratrol as an example. J Gerontol A Biol Sci Med Sci 2012;67:158-67.

29. Wikoff D, Welsh BT, Henderson R, Brorby GP, Britt J, Myers E, et al. Systematic review of the potential adverse effects of caffeine consumption in healthy adults, pregnant women, adolescents, and children. Food Chem Toxicol 2017;109(Pt 1):585-648.

30. Yokoyama O, Yoshida M, Kim SC, Wang CJ, Imaoka T, Morisaki Y, et al. Tadalafil once daily for lower urinary tract symptoms suggestive of benign prostatic hyperplasia: a randomized placebo- and tamsulosin-controlled 12-week study in Asian men. Int J Urol 2013;20:193-201. 